\title{
Role of Rice in Dietary Gadmium Intake of Farming Population with No Known Man-Made Pollution in Japan
}

\author{
Takao Watanabe, Akio Kolzumi, Hiroyoshi Fujita, \\ Mino Kumai and Masayuki Ikeda \\ Department of Environmental Health, Tohoku University \\ School of Medicine, Sendai 980
}

\begin{abstract}
Watanabe, T., Koizumi, A., Fujita, H., Kumai, M. and Ikeda, M. Role of Rice in Dietary Cadmium Intake of Farming Population with No Known Man-Made Pollution in Japan. Tohoku J. exp. Med., 1984, 144 (1), 83-90The 24-hr duplicates of a whole day diet were collected in winter seasons from 1042 farmers in 49 non-polluted regions in Japan, and the amount of boiled rice in each duplicate was compared with the cadmium content in the duplicate to evaluate the role of rice in daily cadmium intake via food. The daily boiled rice intake (in terms of regional geometric means) varied in the range of $720-1,100 \mathrm{~g} /$ day for males and $300-800 \mathrm{~g} /$ day for females, yet positively correlated with whole day dietary cadmium intake in males $(0.07<p<0.08)$, in females $(p<0.01)$ and the combination of the two sexes $(p<0.01)$. The findings, in accordance with other reports, suggest that rice is an important source of cadmium intake among Japanese population even in non-polluted areas. The roles of sake (rice wine) and beer appeared to be quite minor as the cadmium contents were very low.

beer; cadmium; diet; rice; rice wine
\end{abstract}

It has been generally considered that the rice (usually boiled to serve), the major source of energy in traditional Japanese diet (Organisation for Economic Co-operation and Development 1981), is also the leading source of cadmium for Japanese population under environmental cadmium pollution (Nogawa et al. 1978; Nogawa and Ishizaki 1979; Shigematsu et al. 1979). Analysis was made in the present study to examine whether or not such is also the case among the population with no known man-made cadmium pollution. Considerations were further extended to weigh the role of sake (rice wine) and beer as possible sources in cadmium intake.

Received for publication, January 20, 1984.

This work was jointly supported by research grants from Toyota Foundation for 19801982 (No. 80-1-025 and 81-1-121) and Grants-in-Aid for Environmental Science for 1981, 1982, and 1983 (Nos. 56030010, 57030010 and 58030010, respectively) from the Ministry of Education, Science and Culture of the Government of Japan.

Requests for reprints to: Professor Masayuki Ikeda, Department of Environmental Health, Tohoku University School of Medicine, Sendai 980, Japan. 


\section{Materials and Methods}

\section{Total diet collection}

The 24-hr duplicates of a whole day diet (Yamagata and Iwashima 1975; Acheson et al. 1980) were collected in winter, 1977 to 1981, from 1042 adult volunteers (368 males and 674 females, mostly farmers) in 49 areas with no known man-made pollution in Japan, the locations of which were as previously reported (Watanabe et al. 1983). Additional samples were collected from some (209 subjects; 109 males and 100 females) of the same volunteers in immediately adjacent summers. Attentions were paid to ensure that typical daily diets be collected (Watanabe et al. 1984). While the collection included all the food and beverages as much as taken by each examinee, the examinees were specifically asked to store rice in a separate plastic box in order that the weight of rice could be recorded apart from other food and beverages.

\section{Cadmium levels in total diet}

Data were cited from a previous report (Watanabe et al. 1984); the determinations were based on the wet digestion of total diet homogenate followed by automated flameless atomic absorption spectrophotometry for cadmium (Watanabe et al. 1982).

\section{Cadmium levels in alcoholic beverages}

Analyses were conducted as previously described (Watanabe et al. 1982), taking the liquid samples in the place of the diet homogenates.

\section{Statistical analysis}

A preliminary analysis revealed that the amounts of boiled rice taken daily by the examinees of the same decade of age distributed log-normally. Accordingly, a log-normal distribution was assumed for boiled rice intake throughout the present study, so that the intake on group basis was expressed in terms of a geometric mean (GM), a geometric standard deviation (GSD) in parentheses followed by number of samples (N) [i.e., GM (GSD) : N], unless otherwise specified. Dietary intake of cadmium also distributed lognormally (Watanabe et al. 1983).

\section{Results}

\section{Boiled rice intake by region and by sex}

The GM's of daily intake of boiled rice varied in the range of 720-1,100 g/day for males and 300-800 g/day for females depending on the regions (Table 1). There was, however, no geographically biased distribution such as north-south difference.

When a comparison was made between the two sets of GM's for males and females in the regions where 3 or more samples were available for each sex, a significant ( $p<0.01$ by paired $t$ test) difference in boiled rice intake was observed between the two sexes. Correlation between male values and female values was also significant $(p<0.01)$ with a regression line and a correlation coefficient of

$$
Y=319+0.803 X \quad(r=0.538, N=20)
$$

where $Y$ and $X$ are GM's (g/day) of boiled rice intake for males and females, respectively. The equation means that males take about 1.3 times more boiled rice than females in a region where females take $600-650 \mathrm{~g}$ boiled rice daily. 
TABLE 1. Daily boiled rice intake in winter in various regions

\begin{tabular}{|c|c|c|c|c|}
\hline \multirow{3}{*}{$\begin{array}{c}\text { District } \\
\text { number }^{a}\end{array}$} & \multirow{3}{*}{ Prefecture } & \multirow{3}{*}{$\begin{array}{c}\text { Region } \\
\text { number }^{a}\end{array}$} & \multicolumn{2}{|c|}{ Boiled rice intake } \\
\hline & & & Males & Females \\
\hline & & & $\mathrm{GM}^{b}(\mathrm{GSD}): N$ & $\mathrm{GM}^{b}(\mathrm{GSD}): N$ \\
\hline \multirow[t]{2}{*}{10} & Hokkaido & 4 & $754(1.35): 41$ & $627(1.54): 18$ \\
\hline & ibid. & 5 & $: 1^{c}$ & $582(1.33): 18$ \\
\hline \multirow[t]{21}{*}{9} & Aomori & 3 & $-\quad d$ & $525(1.42): 15$ \\
\hline & Miyagi & 35 & $801(1.48): 8$ & $549(1.35): 12$ \\
\hline & ibid. & 36 & - & $473(1.93): 12$ \\
\hline & ibid. & 37 & $1107(1.27): 8$ & $: 1^{c}$ \\
\hline & ibid. & 38 & $797(1.45): 17$ & $794(1.27): 17$ \\
\hline & ibid. & 39 & - & $300(1.50): 20$ \\
\hline & ibid. & 40 & $818(1.52): 10$ & - \\
\hline & ibid. & 41 & $925(1.47): 7$ & $573(1.40): 7$ \\
\hline & ibid. & 42 & $706(1.46): 13$ & $667(1.32): 5$ \\
\hline & ibid. & 43 & - & $581(1.33): 16$ \\
\hline & ibid. & 44 & - & $605(1.60): 40$ \\
\hline & ibid. & 45 & $888,471: 2$ & $542(1.39): 17$ \\
\hline & ibid. & 46 & $917(1.50): 9$ & $793(1.28): 14$ \\
\hline & ibid. & 47 & - & $597(1.45): 39$ \\
\hline & ibid. & 48 & $742(1.45): 9$ & - \\
\hline & ibid. & 50 & $981(1.20): 9$ & - \\
\hline & ibid. & 51 & $913(1.32): 11$ & - \\
\hline & ibid. & 52 & $1128(1.28): 10$ & - \\
\hline & $i b i d$ & 53 & $950(1.56): 3$ & $665(1.39): 16$ \\
\hline & $i b i d$. & 54 & - & $677(1.46): 14$ \\
\hline & Fukushima & 34 & $746(1.46): 17$ & $683(1.40): 6$ \\
\hline \multirow[t]{4}{*}{8} & Tokyo & 6 & - & $323(1.68): 24$ \\
\hline & Saitama & 7 & - & $585(1.42): 28$ \\
\hline & Gunma & 8 & - & $498(1.30): 19$ \\
\hline & $i b i d$ & 9 & - & $665(1.25): 20$ \\
\hline \multirow[t]{4}{*}{7} & Ishikawa & 30 & - & $573(1.61): 19$ \\
\hline & ibid. & 31 & $874(1.35): 9$ & $718(1.26): 9$ \\
\hline & Toyama & 32 & $1247(1.13): 5$ & $743(1.27): 16$ \\
\hline & Niigata & 33 & $987(1.32): 5$ & $553(1.48): 18$ \\
\hline \multirow[t]{2}{*}{6} & Nagano & 10 & - & $591(1.38): 20$ \\
\hline & Aichi & 11 & $903(1.32): 19$ & - \\
\hline \multirow[t]{2}{*}{5} & Wakayama & 13 & $1149(1.44): 40$ & - \\
\hline & ibid. & 14 & $713(1.54): 11$ & $574(1.35): 16$ \\
\hline \multirow[t]{3}{*}{4} & Kagawa & 18 & - & $588(1.50): 21$ \\
\hline & $i b i d$. & 19 & $672(1.74): 17$ & $623(1.54): 5$ \\
\hline & Kochi & 20 & $1055(1.25): 7$ & $754(1.26): 17$ \\
\hline
\end{tabular}




\begin{tabular}{|c|c|c|c|c|}
\hline \multirow{3}{*}{$\begin{array}{l}\text { District } \\
\text { number }^{a}\end{array}$} & \multirow{3}{*}{ Prefecture } & \multirow{3}{*}{$\begin{array}{l}\text { Region } \\
\text { number }^{a}\end{array}$} & \multicolumn{2}{|c|}{ Boiled rice intake } \\
\hline & & & Males & Females \\
\hline & & & $\mathrm{GM}^{b}(\mathrm{GSD}): N$ & $\mathrm{GM}^{b}(\mathrm{GSD}): N$ \\
\hline \multirow{4}{*}{3} & Ehimé & 21 & $1100,691: 2^{c}$ & $666(1.23): 20$ \\
\hline & Shimané & 15 & - & $804(1.33): 20$ \\
\hline & Yamaguchi & 16 & $977(1.33): 17$ & $784(1.31): 4$ \\
\hline & ibid. & 17 & $997(1.38): 20$ & - \\
\hline \multirow[t]{4}{*}{2} & Fukuoka & 22 & - & $714(1.35): 26$ \\
\hline & Kagoshima & 24 & $557(1.69): 4$ & $540(1.39): 19$ \\
\hline & ibid. & 25 & $813(1.01): 5$ & $682(1.35): 26$ \\
\hline & ibid. & 26 & - & $690(1.21): 19$ \\
\hline \multirow[t]{3}{*}{1} & Okinawa & 27 & $691(1.41): 10$ & $536(1.33): 11$ \\
\hline & ibid. & 28 & $617(1.21): 10$ & $412(1.35): 10$ \\
\hline & ibid. & 29 & $809(1.40): 12$ & $468(1.30): 6$ \\
\hline
\end{tabular}

Both males and females are adults of various ages.

a As described in Watanabe et al. (1983).

$b$ Unit: g/day.

$c$ Individual values are shown.

d _ - : No determination was made.

Seasonal variation in boiled rice intake was not significant $(p>0.10$ by paired $t$ test) when the winter and summer intake by the same subjects (109 males in 12 regions and 100 females in 11 regions) were compared.

\section{Correlation between boiled rice intake and dietary cadmium intake}

When the winter GM of boiled rice intake in each of 49 regions was compared with the counterpart value of dietary cadmium intake, the correlation was barely significant $(0.07<p<0.08)$ for males with a correlation coefficient of 0.279 (data available in 29 regions), significant for females $(r=0.493, p<0.01, N=40)$ and also significant when the data for the two sexes were combined ( $r=0.370, p<0.01$, $N=69$ ). It should be added, however, that the boiled rice intake in a certain region with high cadmium intake was not always higher than the values in other regions (Fig. 1), as the small correlation coefficients indicate. The correlation of winter measures on individual basis was statistically significant although the correlation coefficient was rather small, i.e., $r=0.138(p<0.01 ; N=368)$ for males, $r=0.259(p<0.01 ; N=674)$ for females, and $r=0.230(p<0.01 ; N=$ 1042) for the combination.

\section{Effects of urbanization on intakes of boiled rice}

Analysis of boiled rice intake by age (Table 2) revealed that the daily intake varies depending on the decade of ages, and that the amount stays rather constant 


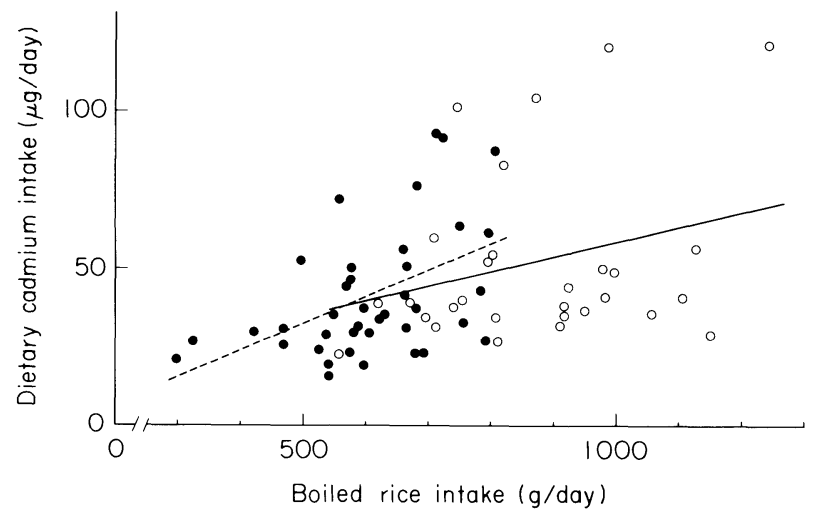

Fig. 1. Correlation between boiled rice intake and dietary intake of cadmium by regions.

Each spot indicate GM of boiled rice intake and dietary intake of cadmium for a given region where 3 or more samples for either sex were available. Open circles are for males and solid ones for females.

The solid line

$$
Y=12.0+0.0466 X(\gamma=0.279,0.07<p<0.08, N=29)
$$

and the broken line

$$
Y=-9.3+0.0836 X(\gamma=0.493, p<0.01, N=40)
$$

are the calculated regression lines for males and for females, respectively, where $X$ is boiled rice intake (GM;g/day) and $Y$ is dietary cadmium intake (GM; $\mu \mathrm{g}$ ) day) by region.

\begin{tabular}{|c|c|c|}
\hline \multirow{2}{*}{ Age ranges } & Males & Females \\
\hline & $\mathrm{GM}^{a}(\mathrm{GSD}): N$ & $\mathrm{GM}^{b}(\mathrm{GSD}): N$ \\
\hline $20-29$ & $911(1.42): 26$ & $596(1.57): 36$ \\
\hline $30-39$ & $909(1.42): \quad 65$ & $632(1.99): 138$ \\
\hline $40-49$ & $902(1.49): 112$ & $632(1.44): 253$ \\
\hline $50-59$ & $863(1.43): 128$ & $567(1.56): 205$ \\
\hline 60 and over & $631(1.41): 37$ & $545(1.48): 40$ \\
\hline
\end{tabular}

TABLE 2. Daily boiled rice intake by age and sex

a Unit: g/day.

at 30-49 years of age with decreasing tendency at advanced ages. Accordingly, female subjects at the ages of 30-49 years were selected from the examinees in the outskirts of the city of Sendai (the urban group of 17 females) and those in other parts of surrounding Miyagi Prefecture (the rural group of 132 females). Daily boiled rice intake in terms of GM (GSD) : $N$ was $321 \mathrm{~g}$ /day (1.34) : 17 for the former group and $626 \mathrm{~g} /$ day (1.64) : 32 for the latter, the difference being statistically significant $(p<0.01)$. Analysis of additional boiled rice samples (34 in total) collected from various parts of Miyagi Prefecture revealed that the cadmium content was $24.5 \mathrm{ng} / \mathrm{g}$ boiled rice (1.50) : 34 as GM (GSD) : N. Based on the boiled 
rice intake and the average cadmium content in boiled rice, the rate of cadmium in boiled rice over cadmium in whole day diet (cited from Watanabe et al. 1984) was calculated on individual basis as

$$
\frac{\text { boiled rice intake }(\mathrm{g}) \times 0.0245(\mu \mathrm{g} / \mathrm{g})}{\text { total dietary cadmium }(\mu \mathrm{g})} \times 100(\%)
$$

When a normal distribution of the rate was assumed, the rate was $39.8 \pm 15.0 \%$ (arithmetic mean \pm arithmetic s.D.) for the urban group and $51.5 \pm 26.2 \%$ for the rural group, the difference being statistically significant $(p<0.05)$.

\section{Cadmium contents in alcoholic beverages}

Through this survey were collected 80 samples of sake (rice wine) which were to be consumed at home by the examinees. The analysis for cadmium disclosed $3.17 \mu \mathrm{g} /$ liter (1.52) : 80 for GM (GSD) : N. The corresponding values for storebought samples were $2.20 \mu \mathrm{g} /$ liter (1.59) : 40 and $2.12 \mu \mathrm{g} /$ liter (1.59) : 29 for first grade and second grade sake, respectively. Analogous studies with several brands of Japanese beer revealed that the cadmium levels were well below $1 \mu \mathrm{g} /$ liter.

\section{Discussion}

Concerning the food item that is the major source of the cadmium intake via diet, Mahaffey et al. (1975) reported that cadmium contents in grain and cereals will account for $22.8 \%$ (11.7 $\mu \mathrm{g} /$ day) of total daily cadmium intake $(52.1 \mu \mathrm{g} /$ day ; the estimate by the 'market baskets' method for a standard 15-20 year-old American male). This percentage for grain and cereals was the largest among the 12 food categories studied. For Japanese diet in particular, Nogawa et al. (1978), Nogawa and Ishizaki (1979) and Shigematsu et al. (1979) reported a significant correlation between cadmium contents in rice consumed and intensity of environmental (nonoccupational) exposure to cadmium, suggesting that rice is a leading source of cadmium in Japanese diet. In fact, Tsuchiya and Iwao (1978) attributed 27 to $74 \%$ of total dietary intake of cadmium to grain and cereals (predominantly rice) in their study in cadmium-polluted and matched control areas in Japan. The positive relations observed in the present study between intake of rice and that of cadmium in diet are in accordance with these reports.

It was also possible to conduct trials for quantitative evaluation. Although no determination of cadmium contents in boiled rice was made on regional basis in the present study, the data are available for cadmium levels in boiled rice samples collected in Miyagi Prefecture, i.e., $24.5 \mathrm{ng} / \mathrm{g}$ as the mean and 10.9 and $55.1 \mathrm{ng} / \mathrm{g}$ as the $95 \%$ lower and upper confidence limits, respectively. Even though the possibility remains that cadmium levels in rice may be variable depending on the regions, the three concentrations were tentatively applied to the cases of minimum and maximum boiled rice intake in each sex (i.e., $557 \mathrm{~g} /$ day in Kagoshima and 1,247 g/day in Toyama for males, and $323 \mathrm{~g}$ /day in Tokyo and $804 \mathrm{~g} /$ day in Shimané for females; Table 1) to estimate the cadmium intake via 
rice. The comparison with corresponding cadmium contents in 24-hour duplicates of diet (values cited from Watanabe et al. 1984) shows that the average share of cadmium intake via rice (estimated as described above) in total dietary cadmium intake is $34.0 \%$ (22.7 to $59.3 \%$ as the range for four cases) when the mean cadmium level in rice is applied. It is $14.5 \%(7.3$ to $26.5 \%)$ with the $95 \%$ lower limit of confidence, and $76.6 \%$ (51.0 to $133.5 \%$ ) with the $95 \%$ upper limit. Such role of rice as the dietary cadmium source may vary depending on the extent of urbanization as urban people eat less rice than rural people. It is quite probable, however, that very high cadmium intake, e.g., over $140 \mu \mathrm{g} /$ day, may not be attributable solely to rice in non-polluted areas, as the rice with cadmium content of over $0.4 \mu \mathrm{g} / \mathrm{g}$ (on unpolished rice basis; the concentration would correspond to ca. $150 \mathrm{ng}$ cadmium/g boiled rice) is administratively excluded from dietary use (Ministry of Health and Welfare 1959).

In contrast, cadmium contents in sake (rice wine) were low in the range of 2-3 $\mu \mathrm{g} /$ liter (Ishizaki et al. 1970 ; also present observation), and those in beer were even lower (present observation). Thus, these two alcoholic beverages, popular in rural males $(75 \%)$ yet much less so among rural females (12\%) (Chiba et al. 1983), will not be major sources of cadmium intake through daily food.

\section{References}

1) Acheson, K.J., Campbell, I.T., Edholm, O.G., Miller, D.S. \& Stock, M.J. (1980) The measurement of food and energy intake in man - an evaluation of some technique. Amer. J. clin. Nutr., 33, 1147-1154.

2) Chiba, K., Koizumi, A., Kumai, M., Watanabe, T. \& Ikeda, M. (1983) A nationwide survey on HDL cholesterol among farmers in Japan. Preventive Med., 12, 508-532.

3) Ishizaki, A., Fukushima, M. \& Sakamoto, M. (1970) Distribution of Cd in biological materials. Part 2. Cadmium and zinc contents of foodstuffs. Jap. J. Hyg., 25, 207 -222 .

4) Mahaffey, K.R., Corneliussen, P.E., Jelinek, C.F. \& Fiorino, J.A. (1975) Heavy metal exposure from foods. Environm. Health Perspect., 12, 63-69.

5) Ministry of Health and Welfare, the Government of Japan (1959) Notification No. 370 , in combination with related guidelines prepared by the local governments concerned.

6) Nogawa, K. \& Ishizaki, A. (1979) A comparison between cadmium in rice and renal effects among inhabitants of the Jinzu River basin. Environm. Res., 18, 410-420.

7) Nogawa, K., Ishizaki, A. \& Kawano, S. (1978) Statistical observations of the doseresponse relationships of cadmium based on the epidemiological studies in the Kakehashi River basin. Environm. Res., 15, 185-198.

8) Organisation for Economic Co-operation and Development (1981) Food Consumption Statistics 1964-1978. OECD, Paris, p. 179.

9) Shigematsu, I., Minowa, M., Yoshida, T. \& Miyamoto, K. (1979) Recent results of health examination on the general population in cadmium-polluted and control areas in Japan. Environm. Health Perspect., 28, 205-210.

10) Tsuchiya, K. \& Iwao, S. (1978) Cadmium intake by the inhabitants in cadmiumpolluted areas in Akita, Ishikawa and Nagasaki Prefectures. Kankyo Hoken (Environmental Health) Report, 44, 86-115. (Japanese)

11) Watanabe, T., Fujita, J. \& Ikeda, M. (1982) A semiautomated system for analysis of 
metals in biological materials and its application to mass determination of cadmium in blood. Toxicol. Letters, 13, 231-238.

12) Watanabe, T., Koizumi, A., Fujita, H., Kumai, M. \& Ikeda, M. (1983) Cadmium levels in the blood of inhabitants in non-polluted areas in Japan with special references to aging and smoking. Environm. Res., 31, 472-483.

13) Watanabe, T., Koizumi, A., Fujita, H., Kumai, M. \& Ikeda, M. (1984) Dietary cadmium intake of farmers in non-polluted areas in Japan, and the relation with blood cadmium levels. Environm. Res., submitted for publication.

14) Yamagata, N. \& Iwashima, K. (1975) Average cadmium intake of the Japanese people. Bull. Inst. Public Health, 24, 18-24. 